\title{
Reply to the letter to the editor by Dr Loukas and Dr Tubbs about our article: Arterial supply of the posterior interventricular sulcus: a CT coronary angiographic study
}

\author{
Ersin Ozturk • Murat Velioglu • Guner Sonmez
}

Received: 1 September 2010/ Accepted: 10 September 2010/Published online: 2 October 2010

(c) Springer-Verlag 2010

We have been very interested in reading the letter to the editor that concerned our article [2] written by Dr. Loukas and Dr. Tubbs entitled "The description of the "Valentine" orientation of the heart" [1]. The authors describe a controversial point in terms used for cardiac anatomy.

Any structure in the body is named according to its anatomical position.

However, cardiac structures are named according to the so-called Valentine position.

The posterior descending artery (PDA) is positioned at the inferior surface of the heart and it runs horizontally towards the ventricular apex. We think that teaching the name of the structures regarding to their anatomical position is true for medical students. But if one use the nomenclature established according to the anatomical position, the majority of the readers could not understand as they know other more common terms. This is a dilemma of this subject for years. We also use the term of PDA for this particular artery because of being a well-known name in the field of clinical cardiology, and in radiologic and anatomic textbooks [3].
We think that changing the terms and beginning using appropriate nomenclature can be started after a consensus. As in the quote from Heraclitus which was interpreted by Plato "panta khorei kai ouden menei" (everything changes and nothing remains still).

Conflict of interest We have no conflict of interest.

\section{References}

1. Loukas M, Tubbs RS (2010) The description of the "Valentine" orientation of the heart. Surg Radiol Anat (in press)

2. Ozturk E, Duran C, Sonmez G, Sildiroglu HO, Velioglu M, Bozlar U, Hagspiel KD (2010) Arterial supply of the posterior interventricular sulcus: a CT coronary angiographic study. Surg Radiol Anat (in press)

3. Uflacker R (2007) Atlas of vascular anatomy: an angiographic approach, 2nd edn. Lippincott Williams \& Wilkins, Philadelphia, p 301

E. Ozturk $(\bowtie) \cdot$ M. Velioglu $\cdot$ G. Sonmez

Department of Radiology,

GATA Haydarpasa Teaching Hospital,

Istanbul, Turkey

e-mail: drersinozturk@gmail.com 